\title{
QUANTIFYING THE SUBJECTIVE BRIGHTNESS OF RETROREFLECTIVE MATERIAL USING MAGNITUDE ESTIMATIONS
}

\author{
Justin S. Graving ${ }^{1}$, Richard A. Tyrrell ${ }^{2}$ \& Stacy A. Balk ${ }^{2}$ \\ ${ }^{1}$ HumanFIRST, ITS institute, University of Minnesota \\ Minneapolis, Minnesota, USA \\ ${ }^{2}$ Department of Psychology, Clemson University \\ Clemson, SC, USA \\ E-mail: justing@me.umn.edu
}

\begin{abstract}
Summary: Ten small patches of retroreflective material were evaluated using a method of magnitude estimation to quantify the effect of changing the coefficient of retroreflection $\left(\mathrm{R}_{\mathrm{A}}\right)$ on brightness perception. Seventeen undergraduates participated. The results show that brightness is tightly linked with $\mathrm{R}_{\mathrm{A}}$. Brightness was influenced more by changes in lower $R_{A}$ than changes in higher $R_{A}$ and follows Steven's power law for brightness. Practical and theoretical implications are discussed.
\end{abstract}

\section{INTRODUCTION}

Retroreflective material is widely used to increase the legibility distance of road signs at night and to enhance the contrast of lane delineators (Olson \& Bernstein, 1977). Similarly, retroreflective material has been shown to increase nighttime pedestrian conspicuity (e.g., Langham \& Moberly, 2003). Retroreflective material is not always optimally retroreflective and varies because of changes in an observers viewing angle, the age of the retroreflector and the accumulation of dirt and grime.

Retroreflective surfaces reflect projected light in the direction of its source. Reflected light leaves a retroreflective surface as a cone that is centered in the direction of the light source. The greatest amount of light is located at the center of the cone and decreases as eccentricity increases. Because of this distribution the amount of retroreflected light reaching an observer's eyes depends on viewing geometry. Small deviations outward from center result in a large drop in retroreflected luminance reaching an observer's eyes. For example, because the observation angle of the retroreflector, the vehicles headlights and the drivers eyes is larger for truck drivers compared to car drivers, at five hundred feet from a retroreflective road sign the amount of luminance reaching the eyes of a truck driver is $68 \%$ of the luminance reaching the eyes of a car driver. At a thousand feet this value drops to 25\% (Sivak, Flannagan and Gellatly, 1991).

Two other factors that decrease retroreflection are the accumulation of dirt and grime on a retroreflector and retroreflector age. Dirt and grime accumulation on semi-trailer markings have been shown to decrease retroreflectivity by $28 \%$ (Olson, Campbell, Massie, Battle, Traube, Aoki, Sato, \& Pettis, 1992). Dirt attenuates retroreflectivity by reducing both incident light and retroreflected luminance. In dark conditions, dirt accumulation on semi trailer retroreflectors has been shown to affect rear impact crashes. Clean retroreflectors have been associated with a $62 \%$ reduction in crashes however dirty retroreflectors have been associated with a $33 \%$ reduction in crashes (Morgan, 2001). Retroreflectivity also decreases throughout the lifespan of a 
retroreflector. Olson et al. (1992) found that retroreflective material starts degrading almost instantly and over 5 years of degrading reflect $30 \%$ less light.

The retroreflected luminance reaching a driver's eyes can vary due to the individual and combined effects of viewing angle, age of the retroreflector, dirt and grime accumulation. These fluctuations can have an impact the distance at which drivers respond (Rumar, 1990). Therefore it is important to understand the influence large fluctuations in retroreflection have on perception. There are a few studies that show decreased retroreflection can cause decreased response distance to retroreflectors worn by pedestrians (i.e. Cassidy Brooks \& Anderson, 2005; Sayer \& Mefford, 2004). Brightness measures have never been reported rather these studies typically only report measures of the retroreflective properties of retroreflective material. Considering that previous research on the relationship between brightness and luminance has shown that increasing luminance increases brightness (Stevens, 1957), in the current experiment it was expected that brightness, measured using magnitude estimations, would show such a relationship with increases in retroreflection. In the current study brightness will be compared to retroreflection whereas typically brightness is compared to luminance.

\section{METHOD}

\section{Subjects}

Seventeen undergraduate Psychology students participated (aged 18 to 21, M=18.8; 9 females) and received extra credit for an introductory Psychology course. Participants were naïve to the hypotheses under investigation.

\section{Experiment design}

The coefficient of retroreflection $\left(\mathrm{R}_{\mathrm{A}}\right)$ was manipulated within-subjects. There were 30 trials per session during which participants gave three brightness magnitude estimates (see procedure for more details). The three estimates were averaged together after data collection resulting in one value for each of the 10 stimuli that was $\log _{10}$ transformed. Brightness magnitude estimations are robust to large deviations between subjects and typically do not need to be normalized to compare between subjects. A new random order of the 30 trials was used for each set of participants. Participant sex was a between-subjects variable.

\section{Materials}

Ten $0.07 \mathrm{~m}$ (height) x $0.12 \mathrm{~m}$ (width; total area: $0.008 \mathrm{~m}^{2}$ ) rectangular patches of retroreflective material (3M Scotchlite 9806 Silver Fabric) were used. A screen printing method was used to reduce the $\mathrm{R}_{\mathrm{A}}$ of the material by applying black ink at 9 densities that occluded varying areas of the retroreflective material. One patch was not treated with ink. After the ink was applied to the material, $\mathrm{R}_{\mathrm{A}}$ measurements were obtained using an ARM Retro-Meter 2 (see Table 1). 
Table 1. Mean (and standard deviation) coefficients of retroreflection $\left(\mathbf{R}_{\mathrm{A}}\right)$ and brightness estimate for the ten retroreflective patches

\begin{tabular}{lllll}
\hline \multicolumn{2}{c}{$\mathrm{R}_{\mathrm{A}}$} & \multicolumn{3}{c}{ Average Brightness } \\
\hline 10 & $(4)$ & 3.46 & $(4)$ \\
38 & $(12)$ & 5.18 & $(5)$ \\
97 & $(16)$ & 8.87 & $(11)$ \\
138 & $(10)$ & 9.24 & $(10)$ \\
227 & $(37)$ & 12.22 & $(14)$ \\
321 & $(5)$ & 13.86 & $(17)$ \\
370 & $(15)$ & 15.19 & $(17)$ \\
421 & $(26)$ & 15.37 & $(17)$ \\
474 & $(15)$ & 15.58 & $(15)$ \\
$581^{*}$ & $(5)$ & 16.11 & $(17)$ \\
\hline
\end{tabular}

Note: Coefficient of retroreflection measured at $0.2^{\circ}$ observation angle and $-4^{\circ}$ entrance angle. Each $\mathrm{R}_{\mathrm{A}}$ measurement was an average of six measurements using the ARM Retro-Meter 2 (*there were three measurements for the patch that measured $\left.581 \mathrm{R}_{\mathrm{A}}\right)$.

\section{Procedure}

Data collection occurred at night on a dark and unused roadway. Participants were seated in an idling test vehicle that was parked $91.4 \mathrm{~m}$ from a stationary device that held the retroreflective material $0.914 \mathrm{~m}$ above the ground. The headlamps of the vehicle were kept on the low-beam setting resulting in 2.62 lux illumination at the position of the retroreflector. The device on which the retroreflectors were mounted was covered in black fabric and was not visible to participants.

Two participants were seated in the test vehicle for most sessions. When there was only one participant, that person sat in the front seat. Otherwise one participant sat in the front passenger seat and the other sat in the middle rear seat. Participants were read the following script describing how to generate a brightness magnitude estimate (adapted from Marks, 1974, p. 40):

"We will show you a series of rectangles that will be mounted a few hundred feet in front of the car. For each rectangle, your task will be to judge how bright the rectangle appears to be. We will ask you to assign a number that stands for the rectangle's brightness. For the first rectangle assign whatever number seems to you the most appropriate to represent its brightness. Then, for the rest of the rectangles, assign other numbers in proportion to their brightness. If one rectangle appears to be three times brighter then another, assign a number that is three times higher; if it appears one-fifth as bright, assign a number that is one-fifth as high. Any type of number -- whole number, decimal, or fraction -- may be used as long as the number is greater than zero." 
Each trial began when the test vehicle headlights were turned on. After the participants wrote down their brightness estimates the headlamps were turned off and the next patch was positioned. Each session lasted approximately 20 minutes.

\section{RESULTS}

Regression analysis was used to determine the extent to which changes in $\mathrm{R}_{\mathrm{A}}$ affected brightness. Increases in $\mathrm{R}_{\mathrm{A}}$ were linearly related to increases in brightness on a $\log -\log$ scale $(F(1,168)=$ $75.95, p<.001)$. Overall, changing the level of the $\mathrm{R}_{\mathrm{A}}$ accounted for $31.1 \%$ of the variability in the brightness (see Figure 1.).

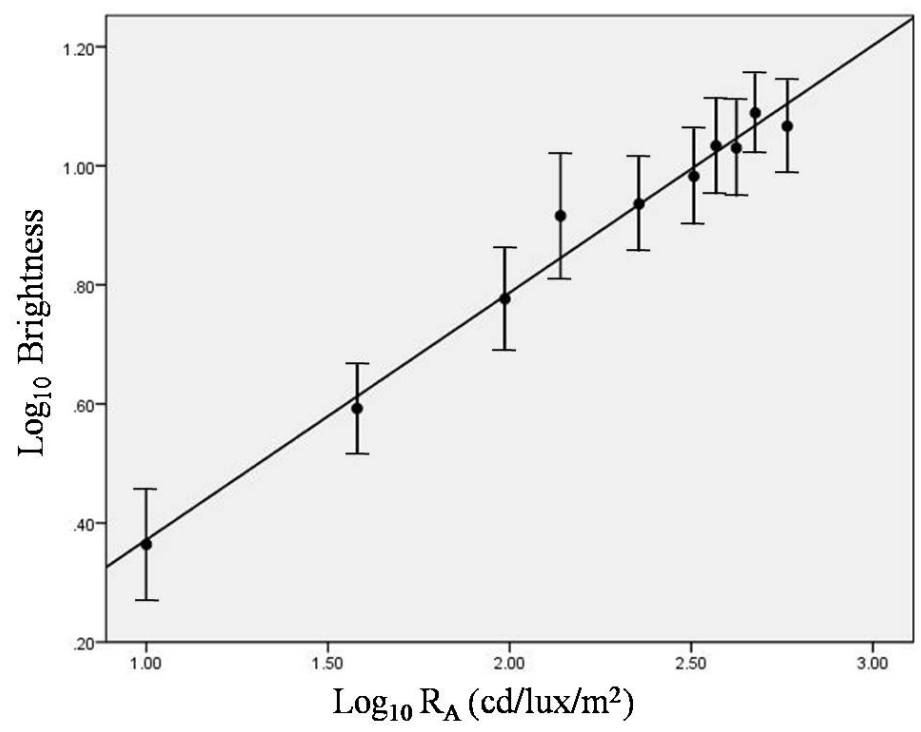

Figure 1. Mean brightness of the 10 levels of $\mathbf{R}_{\mathrm{A}}$. Error bars represent \pm 1 standard error from the mean

The $\log _{10}$ transformed brightness data were analyzed using a repeated measures analysis of variance (ANOVA) with sex as a between-subjects factor and $\mathrm{R}_{\mathrm{A}}$ as a within-subjects factor. Sex did not significantly influence brightness $\left(F(1,15)=.241, p=.631, \eta_{\mathrm{p}}{ }^{2}=.016\right)$, there was a significant effect of $\mathrm{R}_{\mathrm{A}}$ on brightness $\left(F(9,135)=37.19, p<.001, \eta_{\mathrm{p}}{ }^{2}=.713\right)$, and the interaction between sex and $\mathrm{R}_{\mathrm{A}}$ was not significant $\left(F(9,135)=0.173, p=.996, \eta_{\mathrm{p}}{ }^{2}=.011\right)$. Post hoc pairwise comparisons show, in order of lowest $\mathrm{R}_{\mathrm{A}}$ to highest $\mathrm{R}_{\mathrm{A}}$, when comparing each level to its surrounding levels, changes in $\mathrm{R}_{\mathrm{A}}$ had a stronger influence on brightness at lower levels. This effect can be seen in Table 2 . 
Table 2. Bonferroni adjusted $p$-values for the pairwise comparisons for the 10 levels of $\mathbf{R}_{A}$

\begin{tabular}{|c|c|c|c|c|c|c|c|c|c|c|}
\hline & $\mathrm{R}_{\mathrm{A}} 10$ & $R_{A} 38$ & $\mathrm{R}_{\mathrm{A}} 97$ & $\mathrm{R}_{\mathrm{A}} 138$ & $\mathbf{R}_{\mathbf{A}} 227$ & $\mathrm{R}_{\mathrm{A}} 321$ & $\mathrm{R}_{\mathrm{A}} 370$ & $\mathrm{R}_{\mathrm{A}} 421$ & $\mathrm{R}_{\mathrm{A}} 474$ & $\mathrm{R}_{\mathrm{A}} 581$ \\
\hline $\mathrm{R}_{\mathrm{A}} 10$ & - & & & & & & & & & \\
\hline $\mathrm{R}_{\mathrm{A}} 38$ & .001 & - & & & & & & & & \\
\hline $\mathrm{R}_{\mathrm{A}} 97$ & .001 & .016 & - & & & & & & & \\
\hline $\mathrm{R}_{\mathrm{A}} 138$ & $<.001$ & $<.001$ & 1.00 & - & & & & & & \\
\hline $\mathrm{R}_{\mathrm{A}} 227$ & $<.001$ & $<.001$ & .002 & .047 & - & & & & & \\
\hline $\mathrm{R}_{\mathrm{A}} 321$ & $<.001$ & $<.001$ & .001 & .002 & .637 & - & & & & \\
\hline $\mathrm{R}_{\mathrm{A}} 370$ & $<.001$ & $<.001$ & $<.001$ & $<.001$ & .002 & 1.00 & - & & & \\
\hline $\mathrm{R}_{\mathrm{A}} 421$ & $<.001$ & $<.001$ & $<.001$ & $<.001$ & .008 & .456 & 1.00 & - & & \\
\hline $\mathrm{R}_{\mathrm{A}} 474$ & $<.001$ & .007 & .250 & .666 & 1.00 & 1.00 & 1.00 & 1.00 & - & \\
\hline $\mathrm{R}_{\mathrm{A}} 581$ & $<.001$ & $<.001$ & $<.001$ & $<.001$ & .001 & .005 & 1.00 & 1.00 & 1.00 & - \\
\hline
\end{tabular}

\section{DISCUSSION}

Magnitude estimations were used to quantify brightness as the coefficient of retroreflection $\left(\mathrm{R}_{\mathrm{A}}\right)$ was manipulated. The data support the prediction that increasing $\mathrm{R}_{\mathrm{A}}$ would lead to increasing brightness because there was a significant relationship between $\mathrm{R}_{\mathrm{A}}$ and brightness. Brightness was more sensitive when $R_{A}$ was low indicating that relatively small changes in $R_{A}$ were perceptible when $\mathrm{R}_{A}$ was low. On the other hand, when $\mathrm{R}_{\mathrm{A}}$ was high brightness was not as sensitive to fluctuations in $\mathrm{R}_{\mathrm{A}}$. The linear trend shown in Figure 2 indicates that brightness increased as $R_{A}$ increased at the higher levels of $R_{A}$.

The range of the $\mathrm{R}_{\mathrm{A}}$ in this study was large. Still, because the effects of observation angle, retroreflector age, and the accumulation of dirt and grime are additive it is possible that these levels of $R_{A}$ could be encountered outside of this study. The highest $R_{A}$ was 58 times greater than the lowest level of $R_{A}$. The average brightness value associate with the highest $R_{A}$ was almost 4 times greater than the average brightness associated with the lowest level of $R_{A}$. It was not expected that the lowest and highest levels of $\mathrm{R}_{\mathrm{A}}$ and the lowest and highest brightness would be similar in absolute difference. Rather, the data show that the large difference between the lowest and highest $\mathrm{R}_{\mathrm{A}}$ and the range between these values can be discriminated using magnitude estimations. The result is similar to brightness measurements obtained by Stevens (1957). Accordingly, the data from the current study were used to compute an exponent $(n)$ to Steven's power law using equation 1:

$$
n=\frac{\log r}{\log s}
$$

In the current study, using the difference between the highest and lowest $\mathrm{R}_{\mathrm{A}}$ for $s$ and the difference between the highest and lowest brightness for $r$ results in $n=0.37$. According to Stevens (1957) the exponent for subjective brightness units is between 0.3 and 0.5 . Thus the data 
from the current study suggest that the perceptual effects of changes in retroreflectivity follow Stevens's power law for brightness.

A clear limitation in the study was the distribution of the independent variable retroreflection. The screen printing method that was used to generate the different levels of retroreflection was not precise. A different method for creating a complete and equally distributed spectrum of retroreflection should be developed if this study were to be replicated.

As reported by Rumar (1990) increasing retroreflection leads to increased driver response distance yet little is known about the influence of $R_{A}$ on pedestrian conspicuity. A partner study on nighttime pedestrian conspicuity used three of the $R_{A}$ levels from the current study $\left(10 R_{A}\right.$, $137 \mathrm{R}_{\mathrm{A}}$, and $581 \mathrm{R}_{\mathrm{A}}$ ) to investigate the effects of $\mathrm{R}_{\mathrm{A}}$, pedestrian motion, and retroreflector configuration on the distance at which participants respond indicating the presence of a pedestrian. The data show that a retroreflector configuration that presented biological motion affected response distance to a greater extent than manipulating $\mathrm{R}_{\mathrm{A}}$.

\section{ACKNOWLDGEMENTS}

The authors would like to thank Nathan Anderson for his help measuring the coefficient of retroreflection and Lynna Sinakhonerath, Liam H. O'Hara for their help generating the materials.

\section{REFERENCES}

Cassidy, P. E., Brooks, B. E., \& Anderson, N. J. (2005). Size isn't everything: The effects of size and brightness of retroreflective materials on nighttime conspicuity. Proceedings of the Human Factors and Ergonomics Society 49 ${ }^{\text {th }}$ Annual Meeting, 1931-1934.

Langham, M. P., \& Moberly, N. J. (2003). Pedestrian conspicuity research: A review. Ergonomics, 46(4), 345-363

Marks, L. E. (1974). Sensory processes: The new psychophysics. New York: Academic Press.

Morgan, C. (2001, March). The Effectiveness of Retroreflective Tape on Heavy Trailors (Report No.DOT HS 809 222). Washington, DC: U.S. Department of Transportation, National Highway Traffic Safety Administration.

Olson, P. L., \& Bernstein, A. (1977). Determine the Luminous Requirements of Retroreflective highway signing (Report No. UM-HSRI-77-6). Ann Arbor, MI: University of Michigan, Transportation Institute.

Olson, P. L., Campbell, K., Massie, D., Battle, D. S., Traube, E. C., Aoki, T., Sato, T., \& Pettis, L. C. (1992, February). Performance Requirements for Large Truck and Conspicuity Enhancements (Report No. UMTRI-92-8). Ann Arbor, MI: University of Michigan, Transportation Institute.

Rumar, K. (1990). The basic driver error: Late detection. Ergonomics, 33(10), 1281-1290. 
Sayer, J. R., \& Mefford, M. L. (2004b). The roles of retroreflective arm treatments and arm motion in nighttime pedestrian conspicuity (Report No. UMTRI-2004-21). Ann Arbor, MI: University of Michigan, Transportation Research Institute.

Sivak,M., Flannagan, M., and Gellatly, A. (1991, September). The Influence of Truck Driver Eye Position on the Effectiveness of Retroreflective Traffic Signs (Report No. UMTRI-9135). Ann Arbor, MI: University of Michigan, Transportation Institute.

Stevens, S. S. (1957). On the psychophysical law. The Psychological Review, 64(3) 153-181. 